\title{
PENSAMIENTO SOCIAL, ECOLOGÍA Y BIOÉTICA
}

\author{
Social Thinking, Ecology and Bioethics
}

Agustín Ortega Cabrera*

\begin{abstract}
RESUMEN
Este trabajo presenta la enseñanza de la fe de la iglesia católica como la presentan los Papas, como Francisco, sobre el pensamiento social y moral, con su magisterio sobre la ecología integral que supone una bioética global en la defensa de la vida y dignidad de la persona en todas sus fases, formas y dimensiones. Un mensaje que promueve la justicia personal, social y ecológica con un desarrollo humano y global.

\section{Palabras clave:}

Teología, pensamiento social, bioética, ecología.

ABSTRACT

This work presents the teaching of the faith of the Catholic Church on social and moral thinking, as presented by the Popes, like Francisco and his teaching on integral ecology, which assumes a global bioethics in defense of the life and dignity of the person in all its phases, shapes and dimensions. A message that promotes personal, social and ecological justice with a human and global development.
\end{abstract}

\section{Keywords:}

Theology, social thought, bioethics, ecology

* Docente de la Universidad Femenina Sagrado Corazón: agustinortegac@unife.edu.pe 


\section{INTRODUCCIÓN}

La Sagrada Escritura y la teología nos muestran la verdadera utopía que sueña Dios para toda la humanidad: una vida humanizadora, digna, feliz, realizada, plena y eterna. Tal como se manifiesta en la Revelación Bíblica, es el Dios de la vida que, con su Alianza salvífica- su plan e historia de salvación-, nos regala el don de la paz, de la justicia y la liberación integral del mal, de todo ataque a la vida e injusticia. Esta Revelación llega a su culmen con Jesús de Nazaret, el Dios encarnado, que ha venido para traernos vida y vida en abundancia (Jn 10, 10), con su Reino de amor fraterno, de paz y justicia con los pobres de la tierra (Espeja, 2000). Jesús Crucificado-Resucitado, en la Pascua salvadora, nos regala su Espíritu que nos da vida y nos hace hijos de Dios en el amor fraterno, liberándonos del mal y del pecado, de toda esclavitud, ley injusta y muerte (Rm 8; Vidal, 2006).

La primera comunidad de seguidores de Jesús e iglesia acogió toda esta espiritualidad y ética de la vida. Y promueve la defensa de la vida en todas sus fases, desde el inicio con la fecundaciónconcepción del no nacido, y dimensiones de la justicia con los pobres, oprimidos y víctimas (Sierra Bravo, 1997); frente a todo mal, violencia, agresión a la vida e injusticia causadas por los poderosos y ricos. Así nos enseña la Didaché o Enseñanza de los Doce Apóstoles, una de las primeras enseñanzas de este cristianismo originario.

No mates, no adulteres, no corrompas a los menores, no forniques, no robes, no practiques la magia o la hechicería, no mates al hijo por aborto, ni quites la vida al recién nacido. No codicies los bienes del prójimo...Perseguidores de los buenos, aborrecedores de la verdad, amadores de la mentira, desconocedores de los castigos de la justicia, sin afecto por lo bueno y lo justo, despiertos no para el bien sino para el mal; alejados de toda mansedumbre y paciencia, amantes de la vanidad, buscadores de recompensas, que no se compadecen de los pobres, no se ocupan de los afligidos, no reconocen a su creador, asesinos de sus hijos. Corruptores de la obra de Dios por el aborto, ellos rechazan a los indigentes, y los oprimen más en su aflicción, patrocinadores de los ricos, jueces injustos de los pobres errando en todas las cosas (Didaché)

\section{BIOÉTICA Y ECOLOGÍA}

Esta tradición bíblica-apostólica de la iglesia, con la defensa de la vida y dignidad de todo ser humano para una paz justa en un desarrollo humano e integral, es continuada por la iglesia contemporánea y actual (Alarcos, 2006). Así nos lo transmite el Concilio Vaticano II (GS 27) y San Juan Pablo II en su encíclica Evangelium Vitae (EV 3) en contra de todo lo que se opone a la vida:

Todo lo que se opone a la vida, como los homicidios de cualquier género, los genocidios, el aborto, la eutanasia y el mismo suicidio voluntario; todo lo que viola la integridad de la persona humana, como las mutilaciones, las torturas corporales y mentales, incluso los intentos de coacción psicológica; todo lo que ofende a la dignidad humana, como las condiciones infrahumanas de vida, los encarcelamientos arbitrarios, las deportaciones, la esclavitud, la 
prostitución, la trata de blancas y de jóvenes; también las condiciones ignominiosas de trabajo en las que los obreros son tratados como meros instrumentos de lucro, no como personas libres y responsables; todas estas cosas y otras semejantes son ciertamente oprobios que, al corromper la civilización humana, deshonran más a quienes los practican que a quienes padecen la injusticia y son totalmente contrarios al honor debido al Creador (Vaticano II, GS 27; EV 3).

Un texto clave del magisterio de la iglesia con los Papas, como San Juan Pablo II que, continuando con toda esta tradición del humanismo moral y cristiano-católico, expresa esta centralidad, protagonismo y dignidad de la persona con su vida que es sagrada, inviolable y trascendente. Este humanismo y personalismo (Burgos, 2011), acogido y comunicado en lo más valioso que tiene por la enseñanza de la iglesia, lo sigue mostrando San Juan Pablo II en su encíclica sobre la moral, Veritatis Splendor (VS). Transmitiendo y profundizando este principio clave universal de la vida de la persona, en donde cita nuevamente dicho texto del Concilio (GS 27), el Papa denomina "intrínsecamente malos" («intrinsece malum») todos estos actos que van en contra de la vida, de la justicia y del "respeto debido a la persona humana" (VS 80).

San Juan Pablo II, en su mencionada encíclica sobre la vida (EV), señala como símbolos elocuentes del amor a la vida, esos "signos de esperanza":

Cada vez más contraria a la guerra como instrumento de solución de los conflictos entre los pueblos. Y orientada cada vez más a la búsqueda de medios eficaces, pero «no violentos», para frenar la agresión armada. Además, en este mismo horizonte se da la aversión cada vez más difundida en la opinión pública a la pena de muerte, incluso como instrumento de «legítima defensa» social, al considerar las posibilidades con las que cuenta una sociedad moderna para reprimir eficazmente el crimen de modo que, neutralizando a quien lo ha cometido, no se le prive definitivamente de la posibilidad de redimirse. También se debe considerar positivamente una mayor atención a la calidad de vida y a la ecología, que se registra sobre todo en las sociedades más desarrolladas, en las que las expectativas de las personas no se centran tanto en los problemas de la supervivencia cuanto más bien en la búsqueda de una mejora global de las condiciones de vida. Particularmente significativo es el despertar de una reflexión ética sobre la vida. Con el nacimiento y desarrollo cada vez más extendido de la bioética se favorece la reflexión y el diálogo —entre creyentes y no creyentes, así como entre creyentes de diversas religionessobre problemas éticos, incluso fundamentales, que afectan a la vida del hombre (EV 27).

Se visibiliza así ya con el magisterio del San Papa Juan Pablo II, lo que irán ahondando los futuros Papas como Benedicto XVI y (como veremos) de forma más intensa Francisco, esta enseñanza de una bioética global con una ecología integral que promueve la vida, la salud global y la paz de las personas. Por ejemplo, siguiendo toda esta enseñanza de San Juan Pablo II como es EV o VS, 
Francisco ha dejado claro con el actual Catecismo de la Iglesia Católica (CEC) el mal e injusticia de la pena de muerte que, "a la luz del Evangelio, es inadmisible" (CEC 2267). Un signo más, por tanto, del compromiso de la fe e iglesia en esta defensa de la vida y dignidad de la persona en todas sus fases, dimensiones o aspectos.

Todo ello, San Juan Pablo II condena toda forma de violencia:

la violencia contra la vida de millones de seres humanos, especialmente niños, forzados a la miseria, a la desnutrición, y al hambre, a causa de una inicua distribución de las riquezas entre los pueblos y las clases sociales. La violencia derivada, incluso antes de las guerras, de un comercio escandaloso de armas, que favorece la espiral de tantos conflictos armados que ensangrientan el mundo. La siembra de muerte que se realiza con el temerario desajuste de los equilibrios ecológicos, con la criminal difusión de la droga, o con el fomento de modelos de práctica de la sexualidad que, además de ser moralmente inaceptables, son también portadores de graves riesgos para la vida... Las amenazas contra la vida humana, ison tantas sus formas, manifiestas o encubiertas, en nuestro tiempo! Estamos frente a una realidad más amplia, que se puede considerar como una verdadera y auténtica estructura de pecado, caracterizada por la difusión de una cultura contraria a la solidaridad, que en muchos casos se configura como verdadera «cultura de muerte». Esta estructura está activamente promovida por fuertes corrientes culturales, económicas y políticas, portadoras de una concepción de la sociedad basada en la eficiencia. Mirando las cosas desde este punto de vista, se puede hablar, en cierto sentido, de una guerra de los poderosos contra los débiles. La vida que exigiría más acogida, amor y cuidado es tenida por inútil, o considerada como un peso insoportable y, por tanto, despreciada de muchos modos (EV 10, 12).

Tal como se observa, y nos está insistiendo el Papa Francisco, la ética y la fe con la iglesia promueven esta bioética global en una ecología integral, para el cuidado y justicia con todas las víctimas, los pobres, los excluidos y esa casa común que es el planeta tierra. Así nos testimonian todo ello testigos de la vida, de la paz y la justicia como Luther King, Gandhi o Mons. Romero (1979), un santo y mártir del Dios de la vida, de la fe y la justicia con los pobres . En esta línea, los curas y obispos villeros en Argentina (2018), con su comunicado "con los pobres abrazamos la vida", expresan una defensa de la vida integral, desde el inicio frente al aborto o eugenesia y en todos los terrenos; con acciones concretas que realizamos en nuestros barrios para que se viva bien, se viva con dignidad; nuestra opción es por la vida como viene, sin grises... Nuestra experiencia de vecinos, fruto de una consagración, es la de haber aprendido de los villeros a amar y cuidar la vida. No necesitamos agregar más muertes. Nuestros barrios necesitan propuestas de vida digna. Y una sociedad que proteja al más débil.

Y ello frente a estos poderes del capital, del estado e ideológicos que, con sus estructuras sociales e históricas 
de pecado, dañan y niegan la vida de todos estos seres humanos vulnerables, indefensos, empobrecidos y excluidos.

En la actualidad como nos comunica Francisco, por ejemplo, en su encíclica Laudato si' (LS), domina la cultura del descarte y la globalización de la indiferencia ante dicho mal, injusticia y cultura de la muerte. Además, nos debemos liberar de incoherencias e ideologizaciones en torno a la protección de la vida. En este sentido, el Papa afirma:

No puede ser real un sentimiento de íntima unión con los demás seres de la naturaleza si al mismo tiempo en el corazón no hay ternura, compasión y preocupación por los seres humanos. Es evidente la incoherencia de quien lucha contra el tráfico de animales en riesgo de extinción, pero permanece completamente indiferente ante la trata de personas, se desentiende de los pobres o se empeña en destruir a otro ser humano que le desagrada. Cuando no se reconoce en la realidad misma el valor de un pobre, de un embrión humano, de una persona con discapacidad - por poner sólo algunos ejemplos-, difícilmente se escucharán los gritos de la misma naturaleza.

Todo está conectado. Si el ser humano se declara autónomo de la realidad y se constituye en dominador absoluto, la misma base de su existencia se desmorona (LS 91, 117).

Toda esta enseñanza de la fe e iglesia sobre la bioética global y la ecología integral, es razonable, coherente y creíble. Así, como muestran los Papas y su magisterio, la ciencia con "la genética moderna otorga una preciosa confirmación. Muestra que desde el primer instante se encuentra fijado el programa de lo que será ese viviente: una persona, un individuo con sus características ya bien determinadas" (EV 60; DV 7879; Fecha, 2005). En este sentido, la Universidad Jesuita Pontificia Comillas de Madrid (1989), especialista en estas cuestiones de bioética, esclarece que "el conocimiento de la biología molecular del embrión y del feto nos llevan a la convicción de que desde la concepción nos encontramos ante una nueva vida humana distinta de sus progenitores $\mathrm{y}$ que, aunque dependiente y en fase de desarrollo, merece el respeto y la protección de la que gozan todos los seres humanos" . De esta forma, desde la propia filosofía como explica el maestro X. Zubiri, "en el germen está ya todo lo que en su desarrollo constituirá lo que suele llamarse hombre, sin transformación ninguna, sólo por desarrollo; porque el germen es ya un ser humano" (Alburquerque, 2010, 24). Otro pensador no creyente como Gustavo Bueno afirma que "el germen, el embrión, el feto e infante tienen una vida individual propia y autónoma respecto de la madre. Y acabar con su vida es como un regreso o retroceso reaccionario a la época de la barbarie" (Bueno, 2010, 312).

La Iglesia con los Papas, como Francisco, nos llaman pues a un creíble movimiento pro-vida, que esté liberado de incoherencias e ideologizaciones que impiden defender la vida y dignidad de toda persona en todos sus aspectos y desarrollo, junto al cuidado de la hermana tierra. Nos comunica así una conversión personal, social y ecológica integral. Tal como recientemente nos transmite

Por ejemplo, su Homilía del 3er. Domingo de Cuaresma, 18 de marzo de 1979.

Declaración "defensa de la vida humana naciente y protección de toda mujer gestante".

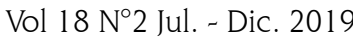


en Gaudete et exsultate (GE), Francisco denuncia y anuncia:

Es nocivo e ideológico el error de quienes viven sospechando del compromiso social de los demás, considerándolo algo superficial, mundano, secularista, inmanentista, comunista, populista. O lo relativizan como si hubiera otras cosas más importantes o como si solo interesara una determinada ética o una razón que ellos defienden. La defensa del inocente que no ha nacido, por ejemplo, debe ser clara, firme y apasionada, porque allí está en juego la dignidad de la vida humana, siempre sagrada, y lo exige el amor a cada persona más allá de su desarrollo. Pero igualmente sagrada es la vida de los pobres que ya han nacido, que se debaten en la miseria, el abandono, la postergación, la trata de personas, la eutanasia encubierta en los enfermos y ancianos privados de atención, las nuevas formas de esclavitud, y en toda forma de descarte. No podemos plantearnos un ideal de santidad que ignore la injusticia de este mundo, donde unos festejan, gastan alegremente $\mathrm{y}$ reducen su vida a las novedades del consumo, al mismo tiempo que otros solo miran desde afuera mientras su vida pasa y se acaba miserablemente (GE 101).

Ecología humana e integral con el buen vivir

Se sigue haciendo memoria de la publicación de la encíclica 'Laudato si' (LS), sobre el cuidado de la casa común del Papa Francisco (Carrera y Puig LL., 2017; Sanz, 2015). En donde destacan eventos como el realizado en Roma, con la participación de diversos grupos, comunidades eclesiales e indígenas, para seguir profundizando sobre este bello e imprescindible documento de LS. Y es que como hemos experimentado en nuestra misión en América Latina con dichas comunidades, LS nos muestra una ecología humana e integral que manifiesta el auténtico buen vivir, como nos transmiten dichas comunidades (Gutiérrez y Seminario, 2018; V. AA., 2016). Es esa inter-relación recíproca y solidaria entre el ser humano, el ambiente y Dios mismo (LS 138 155) con una espiritualidad ecológica y ética del cuidado, que escucha el grito de los pobres de la tierra junto al clamor de la naturaleza. En otro importante documento, los Obispos latinoamericanos (CELAM, 2018), siguiendo la enseñanza de Francisco en LS, han mostrado igualmente toda esta defensa de la vida, de la justicia con los pobres e indígenas y la ecología integral; en contra del capital extractivista de la minería, petroleras, madereras, etc. que están destruyendo a los pueblos, a las culturas y a la naturaleza ambiental.

LS nos presenta esta ecología humana e integral que comunica una verdadera antropología y bioética global, por la que se visibilizan las inherentes fases, dimensiones y aspectos que constituyen la vida de la persona. El ser humano como varón y mujer está conformado por esta ecología y naturaleza humana en su diversidad y complementariedad de aspectos bio-físicos, corporales, sociales, históricos, culturales, espirituales y trascendentes. Es una antropología del don que acoge el regalo de la vida humana (LS 91, 119-120), del cuerpo e identidad personal que, como seres humanos, es preciso respetar y cuidar en todas sus fases, desde el inicio con la fecundación, o dimensiones para realizarnos y desarrollarnos integralmente.

En otro histórico e imprescindible mensaje, esta vez en la XXIV Reunión General de la Academia Pontificia para la Vida, el Papa Francisco nos muestra esta "antropología global con una conversión a la centralidad 
actual de la ecología humana integral, es decir, de una comprensión armoniosa y completa de la condición humana":

Una visión integral de la persona, que trata de articular con creciente claridad todos los vínculos y las diferencias concretas en las que habita la condición humana universal y que nos involucran a partir de nuestro cuerpo. En efecto, nuestro propio cuerpo nos sitúa en una relación directa con el ambiente y con los demás seres vivientes. La aceptación del propio cuerpo como don de Dios es necesaria para acoger y aceptar el mundo entero como regalo del Padre y casa común, mientras una lógica de dominio sobre el propio cuerpo se transforma en una lógica a veces sutil de dominio sobre la creación. Aprender a recibir el propio cuerpo, a cuidarlo y a respetar sus significados, es esencial para una verdadera ecología humana. También la valoración del propio cuerpo en su femineidad o masculinidad es necesaria para reconocerse a sí mismo en el encuentro con el diferente (LS 155).

La dualidad, diversidad y complementariedad de la naturaleza humana que a nivel antropológico, físico, biológico, corporal y afectivo-sexual: se efectúa en la entrega y amor fiel de un hombre con una mujer; y va conformando la institución básica del matrimonio con la familia abierta a la vida, a los hijos, a la solidaridad, al bien común y al compromiso por la justicia (Alburquerque, 2004). Esta ecología humana que responde a la verdad de la persona, frente a toda ideología e individualismo relativista, hay que afirmarla en este don que se nos hace en la naturaleza personal, regalada por Dios desde la fe, con su condición humana, física, biológica, corporal, social y ambiental. Francisco nos enseña:

La ecología humana implica también algo muy hondo: la necesaria relación de la vida del ser humano con la ley moral escrita en su propia naturaleza, necesaria para poder crear un ambiente más digno. Decía Benedicto XVI que existe una «ecología del hombre» porque «también el hombre posee una naturaleza que él debe respetary que no puede manipular a su antojo». De este modo es posible aceptar gozosamente el don específico del otro o de la otra, obra del Dios creador, y enriquecerse recíprocamente. Por lo tanto, no es sana una actitud que pretenda «cancelar la diferencia sexual porque ya no sabe confrontarse con la misma»" (LS 155).

Ciertamente, como nos señala Francisco, Benedicto XVI ya esboza esta enseñanza social y moral, con una ecología integral en una bioética global, en su relevante encíclica "Caritas in Veritate" (Sols Lucia, 2014). Toda esta naturaleza humana, social y ecológica se co-relaciona en la fecundidad de la vida con el amor, el cuidado y la justicia en la familia, con los pobres de la tierra y con esa casa común que es nuestro planeta tierra. Dicha comunión de vida en el amor del varón y la mujer con el matrimonio, la familia, la solidaridad y justicia socio-ambiental: da lugar al buen vivir que presenta este equilibrio y armonía de la vida humana, del cosmos e historia. Romper toda esta cosmovisión antropológica, espiritual e indígena del buen vivir lleva, como afirma repetidamente Francisco, a "la 
colonización" cultural e ideológica, a la destrucción del ecosistema humano, social y ambiental que niega la vida en sus diversas formas.

De esta forma, en el prólogo que hace a un libro de Benedicto XVI (2018), Francisco afirma:

Se vuelve a presentar la misma tentación del rechazo de cualquier dependencia del amor que no sea el amor del hombre por el propio ego, por 'el yo y sus deseos'. Y, como consecuencia, el peligro de la 'colonización' de las conciencias por parte de una ideología que niega la certeza profunda según la cual el hombre existe como varón y hembra, a quienes ha sido asignada la tarea de la transmisión de la vida; esa ideología que llega a la producción planificada y racional de seres humanos y que -tal vez por algún fin considerado 'bueno'llega a considerar lógico y lícito cancelar lo que ya no se considera creado, donado, concebido y generado, sino hecho por nosotros mismos (Alburqueque, 2017; Gutiérrez, 2017).

A este respecto, la Iglesia con la Congregación para la Educación Católica (2019) acaba de sacar un significativo documento, "Varón y mujer los creó", en donde muestra dicha base científica, racional, filosófica y antropológica con "la luz de una ecología plenamente humana e integral". Presenta, por ejemplo, "el núcleo de esa ecología del hombre que se mueve desde el «reconocimiento de la dignidad peculiar del ser humano» y desde la necesaria relación de su vida «con la ley moral escrita en su propia naturaleza»; en donde se hace "necesario reiterar la raíz metafísica de la diferencia sexual: de hecho, hombre y mujer son las dos formas en que se expresa y se realiza la realidad ontológica de la persona humana. Esta es la respuesta antropológica..." (nn. 30 - 24). Tal como estamos viendo que nos enseña, asimismo, la fe e iglesia con los Papas como Francisco en LS y en Amoris laetitia (AL 56, 285, 292, 307; Guerra, 2017).

Las diversas ciencias como la física, la biología, la medicina, las ambientales o las neurociencias (Sanigeneti, 2014) están mostrando toda esta verdad de la naturaleza humana, ecológica y cósmica en donde todo se encuentra unido e inter-relacionado (Sanz, 2015; VV. AA., 2016). En esta línea, el Papa nos recuerda como ya esa referencia ineludible del pensamiento inspirado en la fe, Santo Tomas de Aquino (LS 86, 171), e incluso lo más valioso de pensadores significativos contemporáneos y pioneros en esta perspectiva o cuestiones como son R. Guardini (LS 219) o P. T. de Chardin (LS 83), nos han legado esta cosmovisión: global, unitaria, dinámica y trascendente de la realidad, de la naturaleza y del cosmos. Y cuando no se respeta dicha ecología de la naturaleza (humana, social y ambiental-cósmica) afloran los grandes y graves problemas que padecemos hoy en la humanidad, con las agresiones a la vida del ser humano, a la familia e infancia, a los pobres y al hábitat planetario.

En la Exhortación apostólica Evangelii gaudium me referí al relativismo práctico que caracteriza nuestra época, y que es «todavía más peligroso que el doctrinal». Es la lógica interna de quien dice: «Dejemos que las fuerzas invisibles del mercado regulen la economía, porque sus impactos sobre la sociedad y sobre la naturaleza son daños inevitables». Si no hay 
verdades objetivas ni principios sólidos, fuera de la satisfacción de los propios proyectos y de las necesidades inmediatas, ¿qué límites pueden tener la trata de seres humanos, la criminalidad organizada, el narcotráfico, el comercio de diamantes ensangrentados..." (LS 122-123). Los valores o principios de la vida y dignidad del ser humano, de los pobres y trabajadores, del trabajo con sus derechos como es un salario justo para el obrero y su familia, que está por encima del capital, del beneficio y el mercado (LS 124-129). El destino universal de los bienes, con la equidad en la distribución de los recursos, que tiene prioridad sobre la propiedad que posee siempre un inherente carácter social (LS 93-95). Es una vida de pobreza solidaria en comunión de vida, de bienes y compromiso por la justicia con los pobres frente a los ídolos de la riqueza-ser rico y del tener que se imponen sobre el ser fraterno (LS 222-225; González-Carvajal, 2009).

La razón y el sentido común, como indicamos, nos llevan al convencimiento de que nada más bello, verdadero y bueno que acoger esta antropología y ecología humana e integral con el buen vivir. Así nos lo muestran, como ya apuntamos, todas estas comunidades indígenas e igualmente africanas y diversas espiritualidades como la judía, cristiana, católica y el islam. La antropología y ciencias, en sus diversas ramas, nos transmiten esta unidad psico-humana (Burgos, 2013). Cada uno de los seres humanos, en todo el mundo, compartimos de forma universal estas características humanas y valores comunes, una cosmovisión antropológica y ecológica en la diversidad de culturas.
Un mismo código antropológico y normatividad humana que, como nos muestra toda esta ecología integral y buen vivir, posibilita desarrollarnos y encontrarnos de forma inter-cultual, ética, ecuménica e inter-religiosa (Martínez, 2007). En la búsqueda de la civilización del amor, de la globalización en la solidaridad y la paz frente a toda guerra, violencia e injusticia.

\section{BIOÉTICA GLOBAL PARA UNA ECOLOGÍA INTEGRAL DE LA VIDA}

En su bella e imprescindible exhortación apostólica Gaudete et exsultate (GE, sobre la llamada a la santidad en el mundo contemporáneo), como ya apuntamos, el Papa Francisco nos sigue transmitiendo una profunda bioética global que, en el horizonte de su ecología integral, es poco conocida u ocultada e incluso manipulada:

La defensa del inocente que no ha nacido debe ser clara, firme y apasionada, porque allí está en juego la dignidad de la vida humana, siempre sagrada, y lo exige el amor a cada persona más allá de su desarrollo. Pero igualmente sagrada es la vida de los pobres que ya han nacido, que se debaten en la miseria, el abandono, la postergación, la trata de personas, la eutanasia encubierta en los enfermos y ancianos privados de atención, las nuevas formas de esclavitud, y en toda forma de descarte. No podemos plantearnos un ideal de santidad que ignore la injusticia de este mundo, donde unos festejan, gastan alegremente y reducen su vida a las novedades del consumo, al mismo tiempo que otros solo miran desde afuera 
mientras su vida pasa y se acaba miserablemente (GE 101).

En la línea de otros testigos de la santidad y la fe que promueve toda esta justicia, como Mons. Romero (1979), Francisco nos muestra una ética del cuidado de la vida en todas sus fases, dimensiones y aspectos. Ya en su programática Exhortación apostólica Evangelii Gaudium (EG), por ejemplo, nos llama a cuidar a "los niños por nacer, que son los más indefensos e inocentes de todos, a quienes hoy se les quiere negar su dignidad humana en orden a hacer con ellos lo que se quiera, quitándoles la vida y promoviendo legislaciones para que nadie pueda impedirlo" (EG 213). La defensa de la vida y la dignidad de todo ser humano, como es el niño que está en el vientre de la madre, constituye el pilar básico de la ética y de todos los derechos que se nos comunica como razonable, humanizador y moral. "La sola razón es suficiente para reconocer el valor inviolable de cualquier vida humana, pero si además la miramos desde la fe, 'toda violación de la dignidad personal del ser humano grita venganza delante de Dios y se configura como ofensa al Creador del hombre..." (EG 213).

Más allá de toda ideologización de la ética y de la fe, hay que promover el cuidado y defensa de la vida de toda persona, como es el embrión que habita en la madre, tal como lo afirma el Papa:

Es un fin en sí mismo y nunca un medio para resolver otras dificultades. Si esta convicción cae, no quedan fundamentos sólidos y permanentes para defender los derechos humanos, que siempre estarían sometidos a conveniencias circunstanciales de los poderosos de turno. Frecuentemente, para ridiculizar alegremente la defensa que la Iglesia hace de sus vidas, se procura presentar su postura como algo ideológico, oscurantista y conservador. Sin embargo, esta defensa de la vida por nacer está íntimamente ligada a la defensa de cualquier derecho humano. Supone la convicción de que un ser humano es siempre sagrado e inviolable, en cualquier situación y en cada etapa de su desarrollo (EG 213).

Por lo tanto, toda está ética del cuidado y defensa de la vida de toda persona, con una bioética global, es comprensible, humanista y coherente.

Precisamente porque es una cuestión que hace a la coherencia interna de nuestro mensaje sobre el valor de la persona humana, no debe esperarse que la Iglesia cambie su postura sobre esta cuestión... Quiero ser completamente honesto al respecto. Éste no es un asunto sujeto a supuestas reformas o 'modernizaciones'. No es progresista pretender resolver los problemas eliminando una vida humana (EG 214).

En este sentido, como indicamos, recomendamos leer la declaración "defensa de la vida humana naciente y protección de toda mujer gestante", de la Universidad Pontificia Comillas (1989). En dicha declaración se afirma muy acertadamente:

la defensa de la dignidad y del valor de la vida humana es la primera condición necesaria para encontrar la justicia y la paz en nuestra herida convivencia ciudadana. Dicha defensa constituye el mínimo 
en el que convergen democracia y derechos humanos. En los últimos años, nuevos avances en el conocimiento de la biología molecular del embrión y del feto nos llevan a la convicción de que desde la concepción nos encontramos ante una nueva vida humana distinta de sus progenitores y que, aunque dependiente y en fase de desarrollo, merece el respeto y la protección de la que gozan todos los seres humanos.

Más, todo ello, no debe llevar a la criminalización y condena de la mujer que es una de las víctimas principales de todos estos dramas de la vida y que, muchas veces, no encuentra el acompañamiento o apoyo preciso.

Es verdad, sigue mostrando Francisco, que hemos hecho poco para acompañar adecuadamente a las mujeres que se encuentran en situaciones muy duras, donde el aborto se les presenta como una rápida solución a sus profundas angustias, particularmente cuando la vida que crece en ellas ha surgido como producto de una violación o en un contexto de extrema pobreza. ¿Quién puede dejar de comprender esas situaciones de tanto dolor? (EG 214).

La fe e iglesia nos muestra de la misma forma una fe y ética de la misericordia, que acoge todo sufrimiento como es, por ejemplo, el de la mujer en todas estas situaciones tan difíciles y dolorosas.

Por tanto, como vemos en todo lo anterior, Francisco promueve la bioética global y la ecología integral en la defensa de la vida, de la justicia, bioética social, ecológica y global frente a todo mal, desigualdad e injusticia (humana, social, ambiental y global). Y es que como nos sigue comunicando el Papa en su Encíclica Laudato si (LS), en lugar de resolver los problemas de los pobres y de pensar en un mundo diferente, algunos atinan sólo a proponer una reducción de la natalidad. No faltan presiones internacionales a los países en desarrollo, condicionando ayudas económicas a ciertas políticas de «salud reproductiva)" (LS 50). En coherencia ética, hay que luchar por la vida y dignidad de toda persona, por el niño no nacido, por la justicia con los pobres de la tierra, con los oprimidos, las víctimas de la historia, los seres vivos y el entorno natural.

No puede ser real un sentimiento de íntima unión con los demás seres de la naturaleza si al mismo tiempo en el corazón no hay ternura, compasión y preocupación por los seres humanos. Es evidente la incoherencia de quien lucha contra el tráfico de animales en riesgo de extinción, pero permanece completamente indiferente ante la trata de personas, se desentiende de los pobres o se empeña en destruir a otro ser humano que le desagrada (LS 91).

Frente al relativismo e individualismo, debemos reconocer los valores y principios firmes como es la defensa de la vida en toda la realidad humana, social e histórica. Sin esquizofrenias e incoherencias éticas en la inter-relación inseparable de todas estas cuestiones bioéticas, morales y sociales.

Cuando no se reconoce en la realidad misma el valor de un pobre, de un embrión humano, de una persona con discapacidad -por 
poner sólo algunos ejemplos-, difícilmente se escucharán los gritos de la misma naturaleza. Todo está conectado. Si el ser humano se declara autónomo de la realidad y se constituye en dominador absoluto, la misma base de su existencia se desmorona (LS 117).

Se apertura entonces, como ya apunta Benedicto XVI (CV 54-55), una metafísica y pensamiento de la alteridad, de la inter-relación con los otros y lo otro, sin que nada quede desligado fuera de esa comunión. Tal nos manifiesta la fe en el Dios Uno y Trino, la Trinidad revelada en Jesús, y que asimismo Francisco pone como base para la ecología integral (LS 240). Un encuentro y unidad fraterna en dichos valores o principios universales que como nos muestra la sabiduría moral de la ley natural, transmitida igualmente por la iglesia con los Papas como Francisco (EG 190), hace posible una defensa firme de toda vida y dignidad de la persona. La universalidad de los valores y principios constitutivos de cada persona, compartidos por cualquier ser humano como nos transmite la ley natural, posibilita una consistente ética universal, mundial y global para la promoción de la vida (Comisión teológica internacional, 2009). Una mundialización en la solidaridad de la paz, la justicia y la sostenibilidad ecológica con un desarrollo humano integral. Es esa ecología humana e integral que asume e incluye la naturaleza de la vida personal, corporal, afectivasexual, social, ambiental y cósmica en una retroalimentación recíproca y solidaria (LS 155).

Por todo ello, sigue enseñando el Papa:

Dado que todo está relacionado, tampoco es compatible la defensa de la naturaleza con la justificación del aborto. No parece factible un camino educativo para acoger a los seres débiles que nos rodean, que a veces son molestos o inoportunos, si no se protege a un embrión humano, aunque su llegada sea causa de molestias y dificultades... Es preocupante que cuando algunos movimientos ecologistas defienden la integridad del ambiente, y con razón reclaman ciertos límites a la investigación científica, a veces no aplican estos mismos principios a la vida humana. Se suele justificar que se traspasen todos los límites cuando se experimenta con embriones humanos vivos. Se olvida que el valor inalienable de un ser humano va más allá del grado de su desarrollo (LS 120, 136).

\section{CONCLUSIONES}

Llegando al final de nuestro trabajo, podemos observar la importancia y trascendencia de toda esta ecología integral con una bioética global, como es inspirada por la fe e iglesia con su doctrina social y moral, y que va en la línea de las diversas ciencias o la filosofía. En ellas, se nos transmite una sinergia con la retroalimentación de los diversos aspectos de la vida, de la realidad e historia que son respectivos entre sí. Y que evita visiones parciales, estrechas, ideologizadas e incoherentes de la ética, de la ecología y de la antropología. Dando lugar así a la recta compresión, en una hermenéutica integral, del ser humano y de la misma naturaleza con su auténtico desarrollo. Se perfila pues un auténtico buen vivir en la comunión con los otros, con el hábitat natural y con el Dios de la vida revelado en Cristo, para dar respuesta a todo este grito de los pobres y el clamor de 
la tierra. Esta inter-relación solidaria de todo con todo, en el horizonte de la fe, nos remite al misterio del Dios trinitario que, como se nos manifiesta en Jesús, es comunión y solidaridad.

Tal como afirma Francisco:

Las Personas divinas son relaciones subsistentes, y el mundo, creado según el modelo divino, es una trama de relaciones. Las criaturas tienden hacia Dios, y a su vez es propio de todo ser viviente tender hacia otra cosa, de tal modo que en el seno del universo podemos encontrar un sinnúmero de constantes relaciones que se entrelazan secretamente. Esto no sólo nos invita a admirar las múltiples conexiones que existen entre las criaturas, sino que nos lleva a descubrir una clave de nuestra propia realización. Porque la persona humana más crece, más madura y más se santifica a medida que entra en relación, cuando sale de sí misma para vivir en comunión con Dios, con los demás y con todas las criaturas. Así asume en su propia existencia ese dinamismo trinitario que Dios ha impreso en ella desde su creación. Todo está conectado, y eso nos invita a madurar una espiritualidad de la solidaridad global que brota del misterio de la Trinidad (LS 240).

En la línea de lo más valioso de las ciencias y la filosofía o la misma teología, la fe e iglesia con los Papas como Francisco nos transmiten pues un pensamiento social y moral con su epistemología, que se funda en un conocimiento y antropología de lo real. Esto es, que contempla, acoge e incluye el don de la realidad y la vida en sus diversas formas, dimensiones y aspectos. Una ontología social y moral con una metafísica (cosmovisión global) del ser, del sentido y el hacer que posibilita esta ecología de saberes, integral y la bioética global. Un pensar, sentir y actuar promoviendo el cuidado de toda la vida con el amor fraterno, la solidaridad y la justicia (social, ambiental y mundial). Esa verdadera epistemología desde el sur y de-colonial, con su praxis liberadora e integral de toda dominación colonizadora, de todo mal e injusticia que padecen los seres humanos, los crucificados y víctimas de la historia. Y que cuida la vida de las personas, de los pobres y de esa casa común que es nuestro planeta tierra. Basada en el principio-vida y en la opción por los pobres como sujetos de su promoción integral, que transmite el Dios del amor, la justicia y la paz que culmina en el regalo (Gracia) de la vida plena-eterna.

Al final nos encontraremos cara a
cara frente a la infinita belleza de
Dios (cf. 1 Co 13,12) y podremos
leer con feliz admiración el misterio
del universo, que participará con
nosotros de la plenitud sin fin.
Sí, estamos viajando hacia el
sábado de la eternidad, hacia la
nueva Jerusalén, hacia la casa
común del cielo. Jesús nos dice:
«Yo hago nuevas todas las cosas»
(Ap 21,5 ). La vida eterna será
un asombro compartido, donde
cada criatura, luminosamente
transformada, ocupará su lugar
y tendrá algo para aportar a los
pobres definitivamente liberados
(LS 243).

Así nos lo transmiten los testigos de la fe, estos testimonios espirituales, morales y sociales como son los santos, por ejemplo, los ya citados Mons. Romero o San Francisco de Asís que han vivido 
toda esta unión fraterna con Dios en Cristo, con la iglesia, con los otros, con los pobres y con toda la creación. Y con ellos proclamamos «alabado seas, mi Señor, con todas tus criaturas» (LS $1,87)$. En la comunión eclesial y viva con todos estos santos, siguiendo al Papa Francisco e inspirado en ese espíritu de Asís, se nos visibiliza esa mística y peregrinaje que vive con simplicidad; en una maravillosa armonía con Dios, con los otros, con la naturaleza y consigo mismo. Se advierte pues hasta qué punto son inseparables la preocupación por la naturaleza, la justicia con los pobres, el compromiso con la sociedad y la paz interior (LS 10).

\section{BIBLIOGRAFÍA}

\section{Fuentes Primarias}

Benedicto XVI, Encíclica Caritas in Veritate

Benedicto XVI, Liberar la libertad. Fe $y$ política en el tercer milenio

CELAM, Carta pastoral Discípulos misioneros custodios de la casa común, Discernimiento a la luz de la Laudato si

Comisión teológica internacional, En busca de una ética universal: nueva perspectiva de la ley natural

Concilio Vaticano II, Constitución Pastoral Gaudium et Spes

Congregación para la Educación Católica, Varón y mujer los creó, para una vía del diálogo sobre la cuestión del gender en la educación

Didaché, Enseñanza de los doce apóstoles

Francisco, Exhortación apostólica Amoris laetitia
Francisco, Exhortación Apostólica Evangelii Gaudium

Francisco, Exhortación apostólica Gaudete et exsultate

Francisco, Encíclica Laudato si

Juan Pablo II, Encíclica Evangelium Vitae

Juan Pablo II, Encíclica Veritatis Splendor

Romero, O. (1979). En: http:// servicioskoinonia.org/romero/ homilias/indice.htm

\section{REFERENCIAS}

Alarcos, F. (2006) Bioética global, justicia y teología moral. Madrid: San Pablo.

Alburquerque, E (2004). Matrimonio y familia: teología y praxis cristiana. Madrid: San Pablo.

Alburqueque, E. (2010) La bioética (25 preguntas). Madrid: CCS

Alburquerque, E (2017). Ideología de género, pretensiones y desafíos (25 preguntas). Madrid: CCS.

Bueno, G. (2010) El fundamentalismo democrático. Madrid: Temas de Hoy.

Burgos, J. M. (ed.) (201 1). La filosofía personalista de Karol Wojtyla. Madrid: Palabra

Burgos, J. M (2013) Introducción a la Psicología personalista. Madrid: Dyckinson.

Carrera, J. y Puig LL. (2017) Hacia una ecología integral. Barcelona: CiJ. 
Curas y obispos villeros en Argentina (2018). Con los pobres abrazamos la vida. En: https://www. acde.org.ar/img_mailing/img/con_ los_pobres_abrazamos_la\%20_ vida.pdf

Espeja, J. (2010) Jesucristo. Una propuesta de vida. Madrid: San Pablo

Flecha, J. R. (2005) Bioética. Salamanca: Sígueme.

González-Carvajal, L. (2009). El clamor de los excluidos. Santander: Sal Terrae.

Guerra, R. (2017). "Para comprender Amoris Laetitia". En Medellín no. 168, pp. 409-447.

Gutiérrez, F. ( ( 201017 ). "Consideraciones filosóficoteológicas y educacionales de la Ideología de Género". En Phainomenon no. 2, pp. 65-77. UNIFE.

Gutiérrez, F. y Seminario, N. (2018). "La problemática de los pueblos amazónicos desde la perspectiva de la Doctrina Social de la Iglesia" En Phainomenon, pp. 223, 234. UNIFE.

Martínez, J. L (2007). Ciudadanía, migraciones y religión. San Pablo: Madrid.
Sanigeneti, J. J. (2014) Neurociencias y filosofía del hombre. Madrid: Palabra.

Sanz, E. (ed.) (2015) Cuidar de la tierra, cuidar de los pobres. Laudato Si desde la teología y con la ciencia. Santander: Sal Terrae

Sierra Bravo, R. (1997) Diccionario social de los padres de la iglesia. Madrid: Edibesa.

Sols Lucia, J. (ed.) (2014) Pensamiento social cristiano abierto al Siglo XXI. Santander: Sal Terrae.

Universidad Pontificia Comillas (1989). Defensa de la vida humana naciente y protección de toda mujer gestante. En: https://www.comillas. edu/es/noticias-comillas/1899. comillas-hace-publica-ladeclaracion-defensa-de-la-vidahumana-naciente-y-proteccion-detoda-mujer-gestante

W. AA. (2016). Ecoteología, un mosaico. Bogotá: San Pablo.

Vidal, S. (2006) El proyecto mesiánico de Pablo. Salamanca: Sígueme.

Recepción: 12 de julio del 2019 Aceptación: 16 de agosto del 2019 